\title{
Beneficial effects of green banana biomass consumption in patients with pre-diabetes and type 2 diabetes: a randomised controlled trial
}

\author{
Edna S. Costa ${ }^{1}$, Carolina N. França ${ }^{1,2}$, Francisco A. H. Fonseca ${ }^{1}$, Juliana T. Kato ${ }^{1}$, Henrique T. Bianco ${ }^{1}$, \\ Thiago T. Freitas ${ }^{1}$, Henrique A. R. Fonseca $^{1}$, Antonio Martins Figueiredo Neto ${ }^{3}$ and Maria Cristina Izar ${ }^{1 *}$ \\ ${ }^{1}$ Department of Medicine, Universidade Federal de São Paulo, UNIFESP, São Paulo, SP, Brazil \\ ${ }^{2}$ Department of Health Sciences, Universidade Santo Amaro, UNISA, São Paulo, SP, Brazil \\ ${ }^{3}$ Institute of Physics, Department of Experimental Physics, Universidade de São Paulo, São Paulo, SP, Brazil
}

(Submitted 1 November 2018 - Final revision received 9 January 2019 - Accepted 25 February 2019 - First published online 6 June 2019)

\section{Abstract}

Diabetes mellitus is a global epidemic, characterised as a heterogeneous group of metabolic disorders associated with high risk of CVD. Green banana biomass, which is composed of resistant starches (RS) and cannot be hydrolysed by amylases, delays gastric emptying and modulates insulin sensitivity, thus contributing to improve metabolic disorders. The aim of the present study was to investigate the effects of consumption of RS from green banana biomass on body composition, fasting plasma glucose, glycated $\mathrm{Hb}(\mathrm{HbA} 1 \mathrm{c})$ and homeostasis model assessment of insulin resistance in subjects with pre-diabetes or type 2 diabetes on top of treatment. Middle-aged subjects $(n 113)$ of both sexes with pre-diabetes (HbA1c: 5.7-6.4\%) or diabetes (HbA1c $\geq 6.5 \%$ ) were randomised to receive nutritional support plus green banana biomass ( $40 \mathrm{~g}$ ) (RS: approximately $4.5 \mathrm{~g}, \mathrm{G} 1, n 62)$ or diet alone $(\mathrm{G} 2, n 51)$ for 24 weeks. Body composition, biochemical analyses and dietary intake were evaluated at the beginning and end of the study. In the experimental group (G1), consumption of RS was associated with reduction in HbA1c $(P=0 \cdot 0001)$, fasting glucose $(P=0 \cdot 021)$, diastolic blood pressure $(P=0 \cdot 010)$, body weight $(P=0 \cdot 002)$, BMI $(P=0 \cdot 006)$, waist and hip circumferences $(P<0 \cdot 01)$, fat mass percentage $(P=0.001)$ and increase in lean mass percentage $(P=0.011)$. In controls $(\mathrm{G} 2)$, reductions were observed in waist and hip circumferences $(P<0 \cdot 01)$, HbA1c $(P=0.002)$ and high-density lipoprotein-cholesterol $(P=0 \cdot 020)$. In pre-diabetes or diabetes, non-significant differences were observed in the percentage reduction in HbA1c and fasting glucose in exploratory analyses. Our results indicate that the consumption of bioactive starches is a good dietary strategy to improve metabolic control and body composition.

\section{Key words: Diabetes mellitus: Musa: Starch: Glycaemia: Insulin}

Diabetes mellitus is a heterogeneous group of metabolic abnormalities, associated with microvascular complications related to hyperglycaemia, and other metabolic disorders, implying a higher risk of developing $\mathrm{CVD}^{(1-3)}$. Risk factor control, including intensive glycaemic control, reduces macro- and microvascular complications $^{(1-3)}$. Being a promising nutritional strategy to prevent metabolic diseases, dietary fibre, especially resistant starches (RS), has been widely studied ${ }^{(4-6)}$.

Starches and their derivatives have been widely used in food processing, pharmaceuticals, chemicals, due to their structural plasticity ${ }^{(7)}$. The $\mathrm{C}$-type starches are carbohydrate polymers that have specific crystal adjustability, being found in seeds or rhizomes of various legumes, medicinal plants and crops.

Most RS and slowly digestible starches are C-type starches and cannot be converted to glucose after incubation with digestive enzymes, such as pancreatic amylase and amyloglucosidase at $37^{\circ} \mathrm{C}$. Both RS and slowly digestible starches can decrease the starch hydrolysis rate in vivo and can be considered dietary fibre. The RS are known to modulate insulin sensitivity in healthy and obese volunteers as well as in patients with the metabolic syndrome ${ }^{(8-11)}$, thus contributing to improve the glycaemic response.

There are five types of $\mathrm{RS}^{(12)}$ : RS I, which is a physically inaccessible starch surrounded by a protein matrix and cell wall material; RS II refers to the granular starch with the B- or C-polymorph content, being highly resistant to enzymatic hydrolysis; RS III consists of retrograded starch polymers (mainly amylose) produced when starch reaches near-refrigeration temperatures $\left(4-5^{\circ} \mathrm{C}\right)$ after gelatinisation; RS IV is a chemically modified starch formed either by cross-linking or by adding chemical derivatives; and RS V is the result of a starch-lipid interaction, in which amylose and amylopectin long-branch chains form singlehelical complexes with fatty acids and alcohols.

Abbreviations: G1, green banana biomass group; G2, control group; HbA1c, glycated Hb; HOMA-IR, homeostasis model assessment of insulin resistance; RS, resistant starch.

* Corresponding author: Maria Cristina Izar, email mcoizar@terra.com.br; mcoizar@cardiol.br 
Green banana biomass contains a significant amount of type III RS, and its hydrolysis products are not absorbed in the small intestine. The physiological effects of RS are similar to those of dietary fibres, slowing down gastric emptying, increasing satiety, improving insulin secretion and producing SCFA by fermentation in the small intestine ${ }^{(13)}$. Foods containing RS can modify postprandial glycaemia, prevent hypoglycaemia and reduce hyperglycaemia.

Long-term studies evaluating the RS efficacy in individuals with diabetes or pre-diabetes are scarce in the literature. Therefore, the aim of our study was to investigate the effects of a 24-week supplementation with RS from green banana biomass on changes in levels of glycated $\mathrm{Hb}$ (HbA1c), fasting plasma glucose, homeostasis model assessment of insulin resistance (HOMA-IR) and body composition in subjects with pre-diabetes or type 2 diabetes.

\section{Methods \\ Study design}

The present study was a 24-week, prospective, randomised, open-label trial, with parallel arms and blinded endpoints. The study protocol was approved by the local Ethics Committee (Comitê de Ética em Pesquisa da Universidade Federal de São Paulo, CEP-UNIFESP, CAAE: 48643415.2.0000.5505). It was also registered (NCT03230123) under the BIOMEL Study (Effects of Green Banana BIOmass Consumption in Patients with Pre-diabetes and Diabetes MELlitus) acronym and can be accessed through the Internet (https://clinicaltrials.gov/).

Participants were consecutively included in the study after they read and signed the written informed consent form that is obtained before any study procedure.

The study was conducted at the Department of Medicine, Universidade Federal de Sao Paulo, SP, Brazil. The recruitment process began in February 2016, and the intervention was conducted until March 2017. The calculation of sample size took into account variations in HbA1c, with a type I error $\alpha$ of 0.05 and a type II error $\beta$ of $0 \cdot 2$ ( $80 \%$ power). Reduction in HBA1c between 6-month intervention and baseline was the primary outcome. Reduction in body weight, BMI, waist circumference and percentage of fat mass between assessments were the secondary outcomes.

\section{Inclusion and exclusion criteria}

Patients of both sexes aged $18-85$ years, with HbA1c $\geq 6.5 \%$ for diabetic patients or between 5.7 and $6.4 \%$, for pre-diabetic patients $^{(1-3)}$, on a stable dose of anti-diabetic drugs and without anticipation of dosage changes during the study were included in the study protocol. Subjects using insulin, those who needed change in dose or addition of medication for diabetes, with any malignancy except basal-cell carcinoma, heart failure (New York Heart Association class III or IV), renal failure (estimated glomerular filtration rate $<30 \mathrm{ml} / \mathrm{min}$ ) or under dialysis therapy, AIDS, uncontrolled hypothyroidism (thyroid-stimulating hormone $>10 \mu \mathrm{IU} / \mathrm{ml}$ ), active liver disease, severe psychiatric disorders or any other disease that, in the opinion of the investigator, could interfere with the results were excluded from the study protocol.

\section{Participants}

A total of 142 participants were screened; eleven of them were excluded due to their levels of HbA1c $(<5.7 \% ; n 7)$ or need for addition of anti-hyperglycaemic drugs during the study ( $n$ 4). In all, 131 eligible patients were assigned to either diet intervention plus green banana biomass (G1, $n$ 68) or diet intervention alone $(\mathrm{G} 2, n$ 63) in a $1: 1$ ratio, using a randomnumber generator program. All patients received nutritional support for pre-diabetes and diabetes, according to the current guideline recommendations ${ }^{(14,15)}$. Thirteen patients were discontinued due to their need for insulin (six in G1, seven in G2), and five subjects in G2 did not comply with the diet intervention. Sixty-one individuals in the biomass group (G1) and fifty-two in the control group (G2) concluded the study protocol. Subjects in the G1 group consumed a diet with the addition of green banana biomass ( $40 \mathrm{~g} / \mathrm{d}$, RS: approximately $4.5 \mathrm{~g}$ ) and those in the G2 group consumed diet alone. Body composition measurements and laboratory analyses were collected at baseline and 6 months after the participants were included in the study; dietary questionnaires and nutrition counselling were assessed at baseline, 1, 3 and 6 months (Fig. 1)

\section{Interventions}

Diet plan. The dietary plan was individualised, and all participants with pre-diabetes or diabetes received nutritional support according to the Brazilian Society of Diabetes ${ }^{(16)}$, taking into account the total energy expenditure, based on three standardised menus (20-25 kcal/kg (84-105 kJ/kg) of current weight, for weight reduction; 25-30 kcal/kg (105-126 kJ/kg) of current weight, for weight maintenance; and 30-35 kcal $/ \mathrm{kg}$ $\left(126-146 \mathrm{~kJ} / \mathrm{kg}\right.$ ) of current weight, for weight gain) ${ }^{(17)}$. Macronutrient distribution was adjusted according to the Acceptable Macronutrient Distribution Range ${ }^{(18)}$. Subjects were advised to substitute equivalent foods using a food replacement list based on the MyPlate's food groups ${ }^{(19)}$.

Green banana biomass. Subjects in the intervention group received plastic receptacles containing $1 \mathrm{~kg}$ of green banana biomass, which was kept refrigerated and consumed as two tablespoons $40 \mathrm{~g} / \mathrm{d}$, thus providing approximately $4.5 \mathrm{~g}$ of RS. The product was added to any food preparation without heating. The RS from green banana biomass was standardised and produced by Essência do Vale Alimentos (Cruzeiro) according to the technical recommendations. Nutrition information and the amount of RS in green banana biomass are shown in the online Supplementary Tables S1 and S2 ${ }^{(20)}$. Green banana biomass was well tolerated, and no subject discontinued its use due to any side effect, such as diarrhoea, constipation or abdominal bloating. The green banana biomass was consumed at therapeutic doses, and the participants were recommended to increase water intake. 


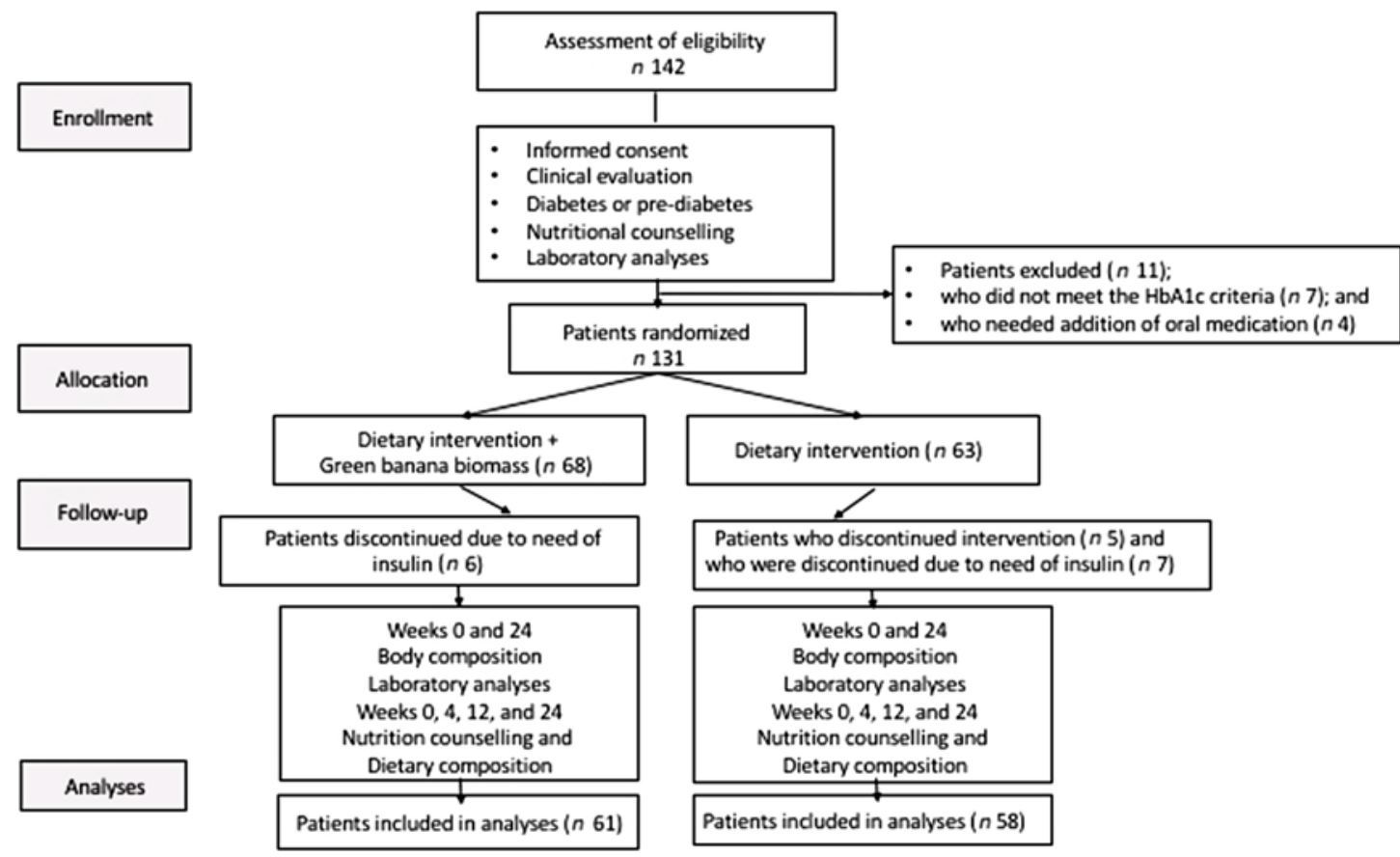

Fig. 1. Design of the BIOMEL Study (Effects of Green Banana BIOmass Consumption in Patients with Pre-diabetes and Diabetes MELlitus). Assessment of eligibility, enrolment, allocation to therapies, follow-up and analyses. A total of 142 participants were screened; eleven were excluded due to their glycated $\mathrm{Hb}(\mathrm{HbA} 1 \mathrm{c})$ levels $<5.7 \%(n 7)$ or to their need to add anti-hyperglycaemic drugs during the protocol $(n 4) ; 131$ eligible patients were assigned to one of two groups, diet intervention plus green banana biomass $(G 1, n 68)$ or diet intervention alone $(G 2, n 63)$ in a 1:1 ratio. All patients received nutritional support for pre-diabetes and diabetes; thirteen patients were discontinued due to need of insulin (six in G1, seven in G2), and five subjects in G2 discontinued the diet intervention; sixty-one individuals in the biomass group (G1) and fifty-two in the control group (G2) concluded the study protocol. Body composition measurements and laboratory analyses were collected at baseline and 6 months; dietary questionnaires and nutrition counselling were assessed at baseline, 1, 3 and 6 months.

\section{Evaluation of food consumption}

Dietary intake was estimated using 24-h food records, applied at baseline, 1, 3 and 6 months. The amounts of energy intake, macro- and micronutrients, total lipids, cholesterol, carbohydrates, fatty acids and vitamins were calculated using the Avanutri Software (Avanutri Revolution, v. 4.0), based on the Brazilian Food Composition ${ }^{(21)}$, Chemical Food Composition tables $^{(22)}$ and information from the Brazilian Institute of Geography and Statistics ${ }^{(23)}$. Standardised FFQ were also applied at the same time points ${ }^{(24)}$. Such questionnaires allow one to objectively record both the frequency (daily, weekly, monthly or annually) and amount (quantities) of food consumption. This tool was aimed at evaluating the diet of population groups with a list of foods and food preparations ${ }^{(24)}$.

The food portion size was based on the Brazilian standard kitchen utensils, and all participants were advised to use them for measuring their own consumption. An adapted FFQ, including vegetable foods, was used to assess the consumption of phytosterols, as described by Martins et al. ${ }^{(25)}$. Compliance with dietary plan and RS consumption was assessed every month, closely monitoring each patient during the procedure. Side effects were also assessed at these visits.

\section{Anthropometric parameters and bioelectrical impedance analysis}

Body composition (weight, height, BMI, waist and hip circumferences and waist:hip ratio) was measured using standard procedures. Bioelectrical impedance was analysed using a portable, battery-powered bioelectrical impedance analyser (Biodynamics 450, $\mathrm{TBW}^{\circledR}$ ). It emits an imperceptible electrical current that travels through the body water compartment, thus assessing the degree of resistance to current flow and determining body weight $(\mathrm{kg})$ and composition.

The operation principle takes into account that the majority of body water is located in the muscle tissue, which offers less impedance to current flow, and thus, greater current flows indicate a greater fat-free mass. The estimated fat-free mass is then used to calculate fat percentage.

Patient information was conducted to the analyser through a connection with the patient's wrist and ankle. Connections to the patient were obtained using standard ECG sensor pad electrodes. Resistance and reactance were measured directly from the body. The analyser used regression analyses and computed as follows: resistance $(R)$, reactance $(X)$, phase angle $(\alpha)$, body capacitance $(C)$, fat-free mass, body cell mass, extracellular mass, fat mass, BMI, BMR, total body water, intracellular water, extracellular water, total body water/fat-free mass and total body water/total weight. Participants were asked to wear light clothes, advised to fast for $4 \mathrm{~h}$, refrain from alcohol, caffeine and chocolate consumption, not to perform physical exercise, discontinue diuretics $24 \mathrm{~h}$ prior to the test and empty the bladder before the procedure. Investigators who performed bioelectrical impedance analysis were blinded to patients' allocation.

\section{Clinical assessment}

Medical visits were performed at baseline and 6 months after intervention. Information on demographic data, medical history, 
concomitant medication and adverse events was recorded. Clinical examination was performed at the same time points, with assessment of vital signs (systolic and diastolic blood pressure and heart rate).

\section{Laboratory parameters}

Overnight fasting blood samples were obtained for all participants at baseline and 6 months of intervention. Commercial kits (Cobas Mira ${ }^{\circledR}$ ) were used in the analysis (automated enzymatic assay) of the following biomarkers: blood glucose, HbA1c, \%, total cholesterol, HDL-cholesterol and TAG.

The Friedewald equation was used to calculate the LDLcholesterol concentration when TAG were $<400 \mathrm{mg} / \mathrm{dl}$ $(4.5 \mathrm{mmol} / \mathrm{l})^{(26)}$. Fasting insulin was measured using the immunofluorometric assay. The HOMA-IR (fasting insulin $(\mu \mathrm{IU} / \mathrm{ml}) \times$ fasting glucose $(\mathrm{mg} / \mathrm{dl}) / 405)$ was calculated, with the cut-off value set at $\geq 2 \cdot 8^{(27)}$.

All analyses were performed at the Central Laboratory, Universidade Federal de São Paulo, UNIFESP, in a blinded fashion.

\section{Statistical analysis}

Categorical variables are expressed as $n$ and percentage and were compared between groups using the Pearson's $\chi^{2}$ test. The Kolmogorov-Smirnov test was used to assess normality. Numerical variables were expressed as means and standard deviations, when Gaussian distribution was observed, or medians and interquartile ranges, when non-Gaussian distribution was observed.

Groups were compared using the Student's $t$ or MannWhitney $U$ tests, as appropriate. Within-group comparisons were carried out using the paired $t$ or Wilcoxon tests. Exploratory analysis of patients with diabetes and pre-diabetes was performed by treatment arm. All analyses were based on the 'intention-to-treat' principle.

Statistical significance was set at $P$ values $<0 \cdot 05$. All analyses were performed using the Statistical Package for Social Sciences (SPSS v. 18.0) programme.

\section{Results \\ Characteristics}

Baseline characteristics were similar in both groups (Table 1). Male subjects were similarly represented in the green banana biomass (G1, 27\%) and control (G2, 18\%) groups (NS); their median ages were 65 (IQR 62-71) years in G1 and 64 (IQR 60-71) years in G2. Part of them had diabetes ( $47 \%$ in G1; $45 \%$ in G2) and the remainder had pre-diabetes.

Many of them had hypertension (62\% in G1; $53 \%$ in G2), whereas others had family history of diabetes ( $55 \%$ in $\mathrm{G} 1$; $27 \%$ in G2). Regarding race, distribution of patients was not different between groups.

\section{Anthropometric measures and vital signs assessment}

Anthropometric data and vital signs at baseline and after 6 months of intervention are shown in Table 2. Subjects with
Table 1. Demographic and clinical characteristics of participants who received nutritional support plus green banana biomass $(\mathrm{G} 1)$ or diet alone (control; G2)*

(Numbers of participants and percentages; medians and interquartile ranges)

\begin{tabular}{|c|c|c|c|c|c|}
\hline \multirow[b]{3}{*}{ Variables } & \multicolumn{4}{|c|}{ Groups } & \multirow[b]{3}{*}{$P$} \\
\hline & \multicolumn{2}{|c|}{ G1 $(n$ 62) } & \multicolumn{2}{|c|}{ G2 (n 51) } & \\
\hline & $n$ & $\%$ & $n$ & $\%$ & \\
\hline Male & 17 & 27 & 9 & 18 & $0 \cdot 219$ \\
\hline Age (years) & & & & & 0.667 \\
\hline Median & \multicolumn{2}{|c|}{65} & \multicolumn{2}{|c|}{64} & \\
\hline Interquartile range & \multicolumn{2}{|c|}{$62-71$} & \multicolumn{2}{|c|}{$60-71$} & \\
\hline Hypertension & 39 & 62 & 27 & 53 & $0 \cdot 190$ \\
\hline Smoking & 30 & 48 & 21 & 41 & 0.501 \\
\hline Alcohol & 9 & 15 & 3 & 6 & 0.290 \\
\hline Family history of diabetes & 34 & 55 & 14 & 27 & 0.053 \\
\hline Diabetes & 29 & 47 & 23 & 45 & 0.510 \\
\hline Pre-diabetes & 33 & 53 & 28 & 55 & \\
\hline \multicolumn{6}{|l|}{ Race } \\
\hline White & 36 & 58 & 18 & 35 & 0.064 \\
\hline Black & 15 & 24 & 18 & 35 & \\
\hline Mulatto & 10 & 16 & 25 & 30 & \\
\hline Asian & 1 & 1 & 0 & 0 & \\
\hline
\end{tabular}

* Categorical variables were compared between groups using the $\chi^{2}$ test. Age was compared between groups using the using the Mann-Whitney $U$ test.

pre-diabetes and diabetes were overweight, with blood pressure of 133/80 mmHg, without difference between groups regarding anthropometric measures or vital signs.

After 6 months of intervention, subjects in the green banana biomass group (G1) showed a reduction in body weight $(P=0.002$, Fig. 2(a)), BMI $(P=0.006$, Fig. 2(b)), waist $(P<0.0001$, Fig. 2(c)) and hip $(P=0.003$, Fig. $2(\mathrm{~d}))$ circumferences and decrease in diastolic blood pressure $(P=0.010)$ (Table 2). Controls showed reduction in waist $(P<0.0001)$ and hip $(P=0.003)$ circumferences.

\section{Laboratory results}

Baseline laboratory parameters were comparable, except for HDL-cholesterol that was lower in the green banana biomass group. After 6 months of intervention, a significant reduction in blood glucose $(P=0.021)$ and HbA1c $(P<0.0001)$ was observed in $\mathrm{G} 1$, whereas a reduction in HbA1c $(P=0.002)$ and HDL-cholesterol $(P=0.020)$ was observed in G2 (Table 3; Fig. 3(a) and (b)). Basal insulin plasma levels and HOMA-IR did not significantly change after interventions (Table 3).

Percentage change between groups in laboratory parameters was tested, and a higher percentage reduction in HDLcholesterol was observed in G2 $(P=0.021$; Mann-Whitney $U$ test), but no difference between groups was observed for other parameters (data not shown).

In pre-diabetes, non-significant differences were observed in the percentage reduction in $\operatorname{HbA1c}(P=0.085)$ and fasting glucose $(P=0.077)$ in our exploratory analyses (Table 4). Treatments did not affect percentage changes in either lipid or glucose parameters in patients with diabetes (Table 4). 
Table 2. Anthropometric characteristics and vital signs of participants who received nutritional counselling plus green banana biomass (G1) or diet alone (control; G2), according to the treatment arm at baseline and end of intervention* (Mean values and standard deviations; medians and interquartile ranges (IQR))

\begin{tabular}{|c|c|c|c|c|c|c|}
\hline \multirow[b]{3}{*}{ Variables } & \multicolumn{4}{|c|}{ Groups } & & \\
\hline & \multicolumn{2}{|c|}{$\mathrm{G} 1(n$ 62) } & \multicolumn{2}{|c|}{$\mathrm{G} 2(n 51)$} & \multicolumn{2}{|l|}{$P$} \\
\hline & Mean & SD & Mean & SD & Between groups at baseline & Within group \\
\hline \multicolumn{7}{|c|}{ Body weight (kg) } \\
\hline Baseline & 77 & 16 & 75 & 14 & 0.434 & $0.002 \dagger$ \\
\hline 6 months & 75 & 15 & 74 & 15 & & $0.879 \ddagger$ \\
\hline \multicolumn{7}{|l|}{$\mathrm{BMI}\left(\mathrm{kg} / \mathrm{m}^{2}\right)$} \\
\hline Baseline & \multirow{2}{*}{\multicolumn{2}{|c|}{$\begin{array}{c}29.8 \\
26.7-33.5\end{array}$}} & & & 0.688 & $0.006 \dagger$ \\
\hline $\begin{array}{l}\text { Median } \\
\text { IQR }\end{array}$ & & & \multicolumn{2}{|c|}{$\begin{array}{c}28 \cdot 9 \\
26 \cdot 5-33 \cdot 1\end{array}$} & & \\
\hline 6 months & \multirow{2}{*}{\multicolumn{2}{|c|}{28.7}} & & & & $0.856 \ddagger$ \\
\hline Median & & & \multicolumn{2}{|c|}{27.9} & & \\
\hline IQR & \multicolumn{2}{|c|}{$26 \cdot 2-32 \cdot 9$} & \multicolumn{2}{|c|}{$26 \cdot 3-31 \cdot 9$} & & \\
\hline \multicolumn{7}{|l|}{$\mathrm{SBP}(\mathrm{mmHg})$} \\
\hline Baseline & 133 & 11 & 133 & 9 & 0.706 & $0.692 \dagger$ \\
\hline 6 months & 133 & 16 & 130 & 15 & & $0.205 \ddagger$ \\
\hline \multicolumn{7}{|l|}{$\mathrm{DBP}(\mathrm{mmHg})$} \\
\hline Baseline & \multirow{3}{*}{\multicolumn{2}{|c|}{$\begin{array}{c}80 \\
74-83\end{array}$}} & & & 0.892 & $0.010 \dagger$ \\
\hline $\begin{array}{l}\text { Median } \\
\text { IQR }\end{array}$ & & & \multicolumn{2}{|c|}{$\begin{array}{c}80 \\
77-82\end{array}$} & & \\
\hline 6 months & \multirow{2}{*}{\multicolumn{2}{|c|}{78}} & & & & $0.085 \ddagger$ \\
\hline Median & & & \multicolumn{2}{|c|}{78} & & \\
\hline IQR & \multicolumn{2}{|c|}{$72-82$} & \multicolumn{2}{|c|}{$74-83$} & & \\
\hline \multicolumn{7}{|c|}{ Waist circumference (cm) } \\
\hline Baseline & 101 & 12 & 99 & 10 & 0.436 & $<0.0001 t$ \\
\hline 6 months & 98 & 11 & 97 & 11 & & $<0.0001 \ddagger$ \\
\hline \multicolumn{7}{|c|}{ Hip circumference $(\mathrm{cm})$} \\
\hline Baseline & 110 & 14 & $108 \cdot 2$ & 10 & 0.668 & $0.003 \dagger$ \\
\hline 6 months & 107 & 12 & $105 \cdot 2$ & 10 & & $0.003 \ddagger$ \\
\hline \multicolumn{7}{|c|}{ Waist:hip ratio (AU) } \\
\hline Baseline & 0.90 & 0.05 & 0.90 & 0.06 & 0.630 & $0.170 \dagger$ \\
\hline 6 months & 0.90 & 0.06 & 0.90 & 0.07 & & $0.890 \ddagger$ \\
\hline
\end{tabular}

SBP, systolic blood pressure; DBP, diastolic blood pressure; AU, arbitrary units.

* Numerical variables were compared between groups using the Student's $t$ or Mann-Whitney $U$ test; within-group comparisons were made using the paired $t$ or Wilcoxon test when appropriate.

† Comparisons between baseline and 6-month periods in G1.

‡ Comparisons between baseline and 6-month periods in G2.

(a)

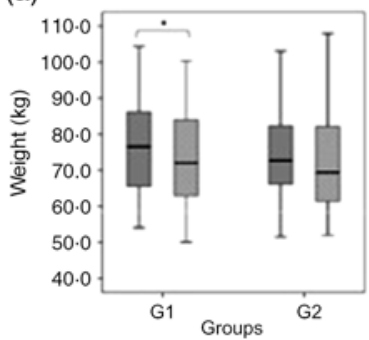

(b)

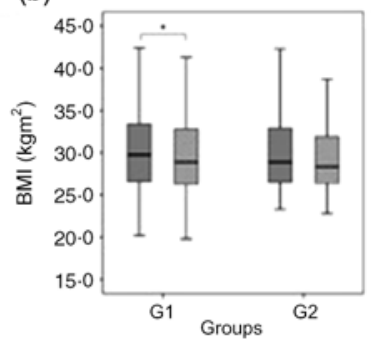

(c)

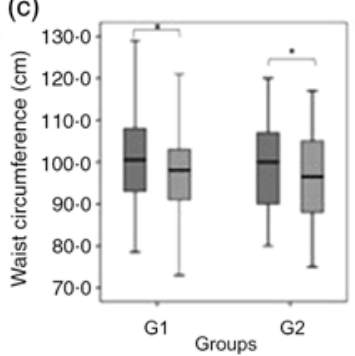

(d)

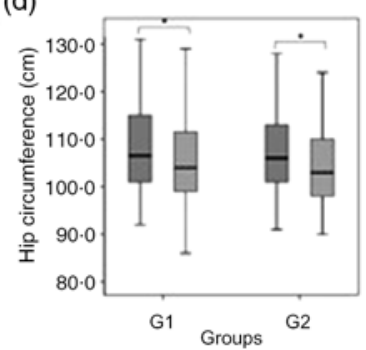

Fig. 2. Box-plots showing the distribution of body weight, $\mathrm{kg} \mathrm{(a),} \mathrm{BMI,} \mathrm{kg} / \mathrm{m}^{2}$ (b), waist circumference, $\mathrm{cm}$ (c) and hip circumference, $\mathrm{cm}$ (d) at baseline ( $\square$ ) and 6-month intervention ( $\square$ ) with resistant starch (RS) from green banana biomass (G1) or controls (G2). Groups were comparable at baseline and 6 months (NS). In G1, weight loss $(P=0.002)(\mathrm{a})$, and reduction in BMI $(P=0.006)(\mathrm{b})$ were observed at 6 months. In both groups, reduction was observed in waist and hip circumferences $(P<0.0001$ and $P=0.003$ in $\mathrm{G} 1$ and $P<0.0001$ and $P=0.003$ in $\mathrm{G} 2$, respectively) (c) and (d). Boxes represent medians, 25th and 75th percentiles; whiskers represent extreme values.

\section{Diet composition}

At baseline, both groups were comparable regarding nutrient intake (Table 5). After 6 months, increase in fibre consumption (G1, $P<0.0001 ; \mathrm{G} 2, P=0.020$; Wilcoxon test) and reduction in both lipid consumption (G1, $P=0.050$, and G2, $P=0.005$; paired $t$ test $)$ and polyunsaturated fat (G1, $P<0.0001$, and G2, $P=0.014$; Wilcoxon test) were observed; an increase in the ingestion of cholesterol was also observed in $\mathrm{G} 1(P=0 \cdot 018$; Wilcoxon test; Table 5).

The ingestion of micronutrients from diet was evaluated at baseline and 6 months. Both groups were comparable regarding intake of nutrients, except for vitamin A (higher in controls, $P=0.041$; Mann-Whitney $U$ test) and manganese (lower in controls, $P=0 \cdot 041$; Student's $t$ test for unpaired samples). In G1, 
Table 3. Laboratory characteristics of participants who received nutritional counselling plus green banana biomass (G1) or diet alone (control; G2) according to treatment arm, at baseline and end of study* (Mean values and standard deviations; medians and interquartile ranges (IQR))

\begin{tabular}{|c|c|c|c|c|c|c|}
\hline \multirow[b]{3}{*}{ Variables } & \multicolumn{4}{|c|}{ Groups } & & \\
\hline & \multicolumn{2}{|c|}{$\mathrm{G} 1(n 62)$} & \multicolumn{2}{|c|}{$\mathrm{G} 2(n 51)$} & \multicolumn{2}{|l|}{$P$} \\
\hline & Mean & SD & Mean & SD & Between groups at baseline & Within group \\
\hline \multicolumn{7}{|c|}{ Total cholesterol $(\mathrm{mg} / \mathrm{dl}) \S$} \\
\hline Baseline & 175 & 43 & 189 & 45 & 0.115 & $0.327 \dagger$ \\
\hline 6 months & 171 & 41 & 182 & 46 & & $0.213 \ddagger$ \\
\hline \multicolumn{7}{|c|}{ HDL-cholesterol $(\mathrm{mg} / \mathrm{dl}) \S$} \\
\hline Baseline & \multirow{2}{*}{\multicolumn{2}{|c|}{45}} & & & 0.004 & $0.787 \dagger$ \\
\hline Median & & & \multicolumn{2}{|c|}{54} & & \\
\hline IQR & \multicolumn{2}{|c|}{$37-55$} & \multicolumn{2}{|c|}{$44-62$} & & \\
\hline 6 months & & & \multirow{2}{*}{\multicolumn{2}{|c|}{53}} & & $0.020 \ddagger$ \\
\hline Median & \multicolumn{2}{|c|}{44} & & & & \\
\hline IQR & \multicolumn{2}{|c|}{$37-53$} & \multicolumn{2}{|c|}{$42-61$} & & \\
\hline \multicolumn{7}{|c|}{ Non-HDL-cholesterol (mg/dl)§ } \\
\hline Baseline & 129 & 6 & 133 & 7 & 0.84 & $0.51 \dagger$ \\
\hline 6 months & 122 & 5 & 132 & 7 & & $0.56 \ddagger$ \\
\hline \multicolumn{7}{|c|}{ LDL-cholesterol $(\mathrm{mg} / \mathrm{dl}) \S$} \\
\hline Baseline & 95 & 35 & 109 & 46 & 0.074 & $0.763 \dagger$ \\
\hline 6 months & 92 & 34 & 103 & 40 & & $0.361 \ddagger$ \\
\hline \multicolumn{7}{|l|}{ TAG $(\mathrm{mg} / \mathrm{dl}) \S$} \\
\hline Baseline & & & & & 0.315 & $0.223 \dagger$ \\
\hline Median & \multirow{2}{*}{\multicolumn{2}{|c|}{$\begin{array}{c}125 \\
99-201\end{array}$}} & \multicolumn{2}{|c|}{108} & & \\
\hline IQR & & & & & & \\
\hline 6 months & & & & & & $0.349 \ddagger$ \\
\hline Median & & & & & & \\
\hline IQR & & & & & & \\
\hline Glucose (mg/ & & & & & & \\
\hline Baseline & & & & & 0.628 & $0.021 \dagger$ \\
\hline Median & & & & & & \\
\hline IQR & & & & & & \\
\hline 6 months & & & & & & $0.287 \ddagger$ \\
\hline Median & & & & & & \\
\hline IQR & & & & & & \\
\hline $\mathrm{HbA1c}(\%)$ & & & & & & \\
\hline Baseline & & & & & 0.384 & $<0.0001 \dagger$ \\
\hline Median & & & & & & \\
\hline IQR & & & & & & \\
\hline 6 months & & & & & & $0.002 \ddagger$ \\
\hline Median & & & & & & \\
\hline IQR & & & & & & \\
\hline Basal insulin & & & & & & \\
\hline Baseline & & & & & 0.444 & $0.660 \dagger$ \\
\hline Median & & & & & & \\
\hline IQR & & & & & & \\
\hline 6 months & & & & & & $0.468 \ddagger$ \\
\hline Median & & & & & & \\
\hline IQR & & & & & & \\
\hline HOMA-IR (Al & & & & & & \\
\hline Baseline & $4 \cdot 1$ & 3.7 & 3.5 & $2 \cdot 6$ & 0.338 & $0.881 \dagger$ \\
\hline 6 months & 4.1 & 3.4 & 3.5 & 2.9 & & $0.939 \ddagger$ \\
\hline
\end{tabular}

$\mathrm{HbA} 1 \mathrm{c}$, glycated $\mathrm{Hb}$; HOMA-IR, homeostasis model assessment of insulin resistance.

* Numerical variables were compared between groups using the Student's $t$ or Mann-Whitney $U$ test; within-group comparisons were made using the paired $t$ or Wilcoxon test when appropriate.

† Comparisons between baseline and 6-month periods in G1.

‡ Comparisons between baseline and 6-month periods in $\mathrm{G} 2$.

$\S$ To convert cholesterol in $\mathrm{mg} / \mathrm{dl}$ to $\mathrm{mmol} / \mathrm{l}$, multiply by 0.0259 . To convert TAG in $\mathrm{mg} / \mathrm{dl}$ to $\mathrm{mmol} / \mathrm{l}$, multiply by 0.0113 . To convert glucose in $\mathrm{mg} / \mathrm{dl}$ to $\mathrm{mmol} / \mathrm{l}$, multiply by 0.0555 .

reduction in the intake of vitamins $\mathrm{B}_{1}(P=0 \cdot 010$; Wilcoxon test $)$ and $\mathrm{E}(P<0.0001$; Wilcoxon test $)$ and increase in the intake of vitamins $\mathrm{B}_{2}(P<0.0001), \mathrm{B}_{5}(P=0.0001), \mathrm{B}_{6}(P<0.0001), \mathrm{B}_{12}$ $(P=0.01), \mathrm{C}(P=0.001)$ and folic acid $(P=0.0001)$ (Wilcoxon test) were observed.

Regarding minerals, increase in the ingestion of $\mathrm{Ca}(P=0 \cdot 011$; paired $t$ test $)$, Se $(P=0.003$; Wilcoxon test $)$ and $\mathrm{K}(P=0.001$; paired $t$ test $)$ and reduction in Na consumption $(P=0 \cdot 004$; paired $t$ test) were observed in G1. In controls, reduction in the intake of vitamin $\mathrm{E}(P=0.009$; Wilcoxon test $)$; increase in the intake of vitamins $\mathrm{B}_{6}(P=0.02$; Wilcoxon test $)$, folic acid $(P=0 \cdot 048$; Wilcoxon test), $\mathrm{B}_{5}(P=0.02$; Wilcoxon test $), \mathrm{K}(P=0.02)$ and $\mathrm{Mn}(P=0.03)$; and reduction in Na consumption ( $P=0.001$; paired $t$ test for all) were observed (data not shown). 
(a)

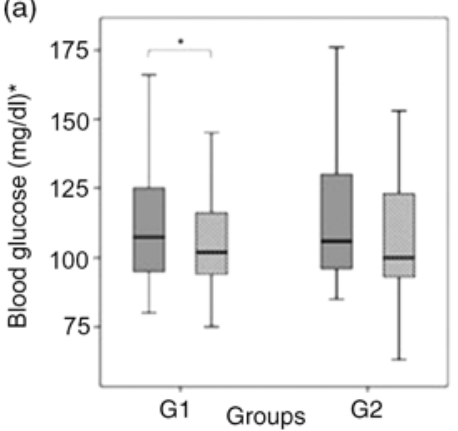

(b)

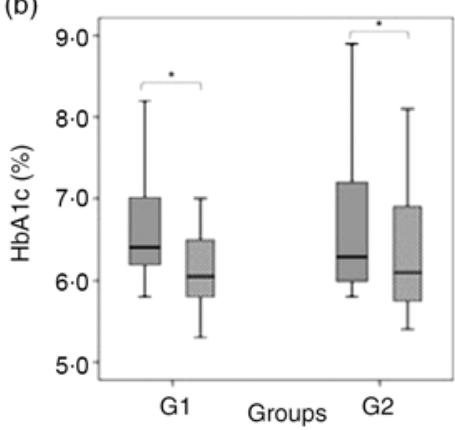

Fig. 3. Box-plots showing the distribution of blood glucose, $\mathrm{mg} / \mathrm{dl}(\mathrm{a})$, and glycated $\mathrm{Hb}(\mathrm{HbA1c}), \%(\mathrm{~b})$ at baseline $(\square)$ and after 6 months of intervention ( $\square$ ) with resistant starch (RS) from green banana biomass (G1) or controls (G2). Groups were comparable at baseline and 6 months (NS). Significant reductions were observed in blood glucose $(P=0.021)$ and $\mathrm{HbA1c}(P<0.0001)$ in $\mathrm{G} 1$, and in HbA1c $(P=0.002)$ in $\mathrm{G} 2(\mathrm{a})$ and (b). Boxes represent medians, 25th and 75th percentiles; whiskers represent extreme values. * To convert glucose in $\mathrm{mg} / \mathrm{dl}$ to $\mathrm{mmol} / \mathrm{l}$, multiply by 0.0555 .

Table 4. Exploratory analyses of change values (\% change from baseline) in lipid and glucose metabolism parameters, by group and the presence of type 2 diabetes or pre-diabetes† (Medians and interquartile ranges (IQR))

\begin{tabular}{|c|c|c|c|c|c|}
\hline \multirow[b]{2}{*}{ Variables } & \multicolumn{2}{|c|}{ G1 ( $n$ 62)‡ } & \multicolumn{2}{|c|}{ G2 $(n 51) \S$} & \multirow[b]{2}{*}{$P$} \\
\hline & Median & IQR & Median & IQR & \\
\hline \multicolumn{6}{|l|}{ Total cholesterol } \\
\hline Pre-diabetes & -1.04 & -11.23 to 8.58 & 0.18 & -14.07 to 8.01 & 0.951 \\
\hline Diabetes & 1.99 & -16.43 to 12.57 & $-3 \cdot 15$ & -15.77 to 7.93 & 0.669 \\
\hline \multicolumn{6}{|l|}{ HDL-cholesterol } \\
\hline Pre-diabetes & -1.79 & -7.15 to 7.69 & -4.06 & $-10 \cdot 15$ to 1.41 & 0.205 \\
\hline Diabetes & 0.00 & -5.58 to 8.40 & $-6 \cdot 01$ & -13.81 to 5.40 & $0.041^{*}$ \\
\hline \multicolumn{6}{|l|}{ LDL-cholesterol } \\
\hline Pre-diabetes & 0.00 & $-17 \cdot 20$ to 25.32 & $3 \cdot 13$ & -8.75 to 16.31 & 0.741 \\
\hline Diabetes & $6 \cdot 61$ & -31.61 to 27.51 & $-3 \cdot 33$ & -17.92 to 21.35 & 0.86 \\
\hline \multicolumn{6}{|c|}{ Non-HDL-cholesterol } \\
\hline Pre-diabetes & -8.03 & -35.71 to $15 \cdot 27$ & $2 \cdot 64$ & -6.41 to 17.01 & 0.248 \\
\hline Diabetes & -0.17 & -32.00 to 13.83 & -4.76 & -29.21 to 7.03 & 0.903 \\
\hline \multicolumn{6}{|l|}{ TAG } \\
\hline Pre-diabetes & $-5 \cdot 26$ & -28.63 to 18.62 & -0.92 & -18.14 to 29.77 & 0.310 \\
\hline Diabetes & -3.81 & -27.60 to 22.81 & 0.24 & -14.87 to 42.29 & 0.174 \\
\hline \multicolumn{6}{|l|}{ Glycaemia } \\
\hline Pre-diabetes & -1.98 & $-6 \cdot 13$ to 3.76 & -4.76 & -11.37 to 1.06 & $0.077^{\star}$ \\
\hline Diabetes & -7.84 & -12.53 to 4.69 & $2 \cdot 31$ & -21.74 to 17.05 & 0.253 \\
\hline \multicolumn{6}{|l|}{$\mathrm{HbA} 1 \mathrm{c}$} \\
\hline Pre-diabetes & -6.25 & -7.87 to -1.56 & $-3 \cdot 25$ & -5.15 to 0.00 & $0.085^{*}$ \\
\hline Diabetes & $-6 \cdot 15$ & -10.77 to -0.70 & $-5 \cdot 79$ & -11.94 to 3.85 & 0.985 \\
\hline \multicolumn{6}{|l|}{ Insulin } \\
\hline Pre-diabetes & -7.87 & -25.17 to 26.92 & 0.00 & -42.24 to 13.41 & 0.367 \\
\hline Diabetes & $-5 \cdot 82$ & -31.55 to 22.85 & 1.40 & -23.64 to 31.99 & 0.528 \\
\hline \multicolumn{6}{|l|}{ HOMA-IR } \\
\hline Pre-diabetes & -10.71 & -27.72 to 30.47 & -5.05 & -44.28 to 10.89 & 0.296 \\
\hline Diabetes & -14.91 & -34.86 to 14.30 & 5.49 & -45.14 to 55.73 & 0.273 \\
\hline
\end{tabular}

G1, green banana biomass group; G2, control group; HbA1c, glycated Hb; HOMA-IR, homeostasis model assessment of insulin resistance. ${ }^{*} P<0.05$, Mann-Whitney $U$ test.

$\dagger$ Medians were compared using the Mann-Whitney $U$ test.

$\ddagger$ Pre-diabetes ( $n$ 33); diabetes ( $n 29$ ).

$\S$ Pre-diabetes ( $n$ 28); diabetes ( $n$ 23).

\section{Bioelectrical impedance}

In the bioelectrical impedance parameters, no significant difference between groups was observed at baseline (Table 6). Consumption of RS promoted reduction in body weight $(P=0.002)$ and fat mass percentage $(P=0.002)$ and increase in lean mass percentage $(P=0.011$; paired $t$ test for all; Table 6).

\section{Discussion}

Our study showed that in subjects with pre-diabetes and diabetes the consumption of RS from green banana biomass added to a diet for 6 months was followed by reduction in body weight, BMI, waist and hip circumferences, diastolic blood pressure, decrease in glucose and HbA1c levels, decrease in fat mass and increase in lean mass percentages. 
Table 5. Diet composition of participants who received nutritional counselling plus green banana biomass (G1) or diet alone (control; G2), according to group, at baseline and after intervention* (Mean values and standard deviations; medians and interquartile ranges (IQR))

\begin{tabular}{|c|c|c|c|c|c|c|}
\hline \multirow[b]{3}{*}{ Variables } & \multicolumn{4}{|c|}{ Groups } & & \\
\hline & \multicolumn{2}{|c|}{$\mathrm{G} 1(n 61)$} & \multicolumn{2}{|c|}{$\mathrm{G} 2(n 47)$} & \multicolumn{2}{|c|}{$P$} \\
\hline & Mean & SD & Mean & SD & Between groups & Within group \\
\hline \multicolumn{7}{|c|}{ Total energy (kcal)§ } \\
\hline Baseline & 1276 & 384 & 1179 & 311 & $0 \cdot 160$ & $0.180 \dagger$ \\
\hline 6 months & 1357 & 362 & 1217 & 328 & & $0.650 \ddagger$ \\
\hline \multicolumn{7}{|l|}{ Proteins (\%) } \\
\hline Baseline & $22 \cdot 1$ & $5 \cdot 7$ & $21 \cdot 0$ & $7 \cdot 0$ & 0.390 & $0.600 \dagger$ \\
\hline 6 months & 22.5 & 5.9 & 21.0 & $6 \cdot 6$ & & $0.750 \ddagger$ \\
\hline \multicolumn{7}{|c|}{ Carbohydrates (\%) } \\
\hline Baseline & $50 \cdot 0$ & 8.5 & $50 \cdot 2$ & $9 \cdot 2$ & 0.900 & $0.190 \dagger$ \\
\hline 6 months & $52 \cdot 3$ & 8.4 & $55 \cdot 2$ & 11.0 & & $0.009 \ddagger$ \\
\hline \multicolumn{7}{|l|}{ Lipids (\%) } \\
\hline Baseline & $27 \cdot 7$ & 6.9 & $28 \cdot 6$ & 7.4 & 0.500 & $0.050 \dagger$ \\
\hline 6 months & $25 \cdot 2$ & $7 \cdot 1$ & 23.6 & 7.4 & & $0.005 \ddagger$ \\
\hline \multicolumn{7}{|c|}{ Cholesterol (mg) } \\
\hline Baseline & & & & & 0.470 & $0.018 \dagger$ \\
\hline Median & \multirow{2}{*}{\multicolumn{2}{|c|}{$\begin{array}{c}155 \\
93.9-200\end{array}$}} & \multicolumn{2}{|c|}{167} & & \\
\hline IQR & & & \multicolumn{2}{|c|}{ 87-182 } & & \\
\hline 6 months & & & & & & $0.130 \ddagger$ \\
\hline Median & \multirow{2}{*}{\multicolumn{2}{|c|}{$\begin{array}{c}181 \\
118-233\end{array}$}} & \multirow{2}{*}{\multicolumn{2}{|c|}{$\begin{array}{c}162 \\
108-219\end{array}$}} & & \\
\hline IQR & & & & & & \\
\hline \multicolumn{7}{|l|}{ SFA $(g)$} \\
\hline Baseline & $10 \cdot 8$ & $7 \cdot 2$ & $10 \cdot 0$ & 4.8 & 0.530 & $0.660 \dagger$ \\
\hline 6 months & 11.4 & $6 \cdot 8$ & 8.3 & 4.4 & & $0.020 \ddagger$ \\
\hline \multicolumn{7}{|l|}{ PUFA (g) } \\
\hline Baseline & & & & & 0.103 & $<0.0001 \dagger$ \\
\hline Median & \multirow{2}{*}{\multicolumn{2}{|c|}{$\begin{array}{c}9 \cdot 2 \\
5 \cdot 3-13 \cdot 6\end{array}$}} & \multirow{2}{*}{\multicolumn{2}{|c|}{$\begin{array}{c}8.0 \\
3.3-12 \cdot 1\end{array}$}} & & \\
\hline IQR & & & & & & \\
\hline 6 months & \multirow{4}{*}{\multicolumn{2}{|c|}{$\begin{array}{c}5 \cdot 1 \\
2 \cdot 5-8 \cdot 5\end{array}$}} & & & & $0.014 \ddagger$ \\
\hline Median & & & \multirow{3}{*}{\multicolumn{2}{|c|}{$\begin{array}{c}4.7 \\
2.9-7.5\end{array}$}} & & \\
\hline IQR & & & & & & \\
\hline \multicolumn{4}{|l|}{ MUFA (g) } & & & \\
\hline Baseline & $10 \cdot 7$ & $5 \cdot 0$ & $9 \cdot 8$ & $4 \cdot 2$ & 0.340 & $0.437 \dagger$ \\
\hline 6 months & 11.2 & $6 \cdot 1$ & 9.2 & 4.3 & & $0.346 \ddagger$ \\
\hline \multicolumn{7}{|l|}{ Fibre $(\mathrm{g})$} \\
\hline Baseline & & & & & 0.090 & $<0.0001 \dagger$ \\
\hline Median & & & & & & \\
\hline IQR & & & & & & \\
\hline 6 months & & & & & & $0.002 \ddagger$ \\
\hline Median & & & & & & \\
\hline IQR & & & & & & \\
\hline Phytosterols & & & & & & \\
\hline Baseline & 68.9 & 34.9 & $69 \cdot 6$ & $31 \cdot 6$ & 0.980 & $0.460 \dagger$ \\
\hline 6 months & $69 \cdot 6$ & 44.0 & 73.4 & 34.6 & & $0.400 \ddagger$ \\
\hline
\end{tabular}

The diet intervention reduced waist and hip circumferences as well as HbA1c and HDL-cholesterol blood concentrations.

RS have been analysed in animal models and kinetic and short-term human studies, and their effects on glucose metabolism, inflammation, and prevention of diabetes were evaluated.

The hypoglycaemic effects of low, medium and high doses of RS II were studied in rats with type 2 diabetes $^{(28)}$. Regulation in the levels of plasma and liver lipids, fructosamine, oral glucose tolerance test, insulin and glucose metabolism was improved in diabetic rats taking RS II. In the pancreas, the expression levels of insulin receptor substrates 1 and 2 were enhanced after RS II was consumed. These results from a study with diabetic rats fed RS suggested that decreases in blood glucose levels are regulated through the alteration in the expression levels of genes related to glucose metabolism. In other study with Zucker diabetic fatty rats, RS decreased the levels of HbA1c, blood glucose, HOMA-IR, and delayed the onset of diabetes as compared with other nondigestible starch-based diets ${ }^{(29)}$. In conventionalised mice fed RS under a Western diet, insulin sensitivity was improved and Western diet-induced changes in microbiome composition were restored. Reduction was observed in the gene expression of adipose tissue macrophage markers and caecal concentrations of various bile acids. These effects of RS were also observed in germ-free littermates. Improvement in insulin levels was independent of the microbiota and may involve changes in the bile acid cycle and adipose tissue immune modulation ${ }^{(30)}$. 
Table 6. Bioelectrical impedance characteristics of participants who received nutritional counselling plus green banana biomass (G1) or diet alone (control; G2), according to the treatment arm at baseline and 6 months after intervention* (Mean values and standard deviations)

\begin{tabular}{|c|c|c|c|c|c|c|}
\hline \multirow[b]{3}{*}{ Variables } & \multicolumn{4}{|c|}{ Groups } & & \\
\hline & \multicolumn{2}{|c|}{$\mathrm{G} 1(n 60)$} & \multicolumn{2}{|c|}{$\mathrm{G} 2(n 48)$} & \multicolumn{2}{|l|}{$P$} \\
\hline & Mean & SD & Mean & SD & Between groups at baseline & Within group \\
\hline \multicolumn{7}{|l|}{ Weight (kg) } \\
\hline Baseline & $76 \cdot 7$ & $15 \cdot 7$ & 74.7 & $14 \cdot 0$ & \multirow[t]{2}{*}{0.434} & $0.002 \dagger$ \\
\hline \multicolumn{6}{|l|}{$\alpha(\stackrel{\circ}{)})$} & \\
\hline Baseline & $7 \cdot 3$ & 1.5 & 7.9 & $2 \cdot 7$ & \multirow[t]{2}{*}{0.330} & $0.004 \dagger$ \\
\hline 6 months & $6 \cdot 7$ & 0.8 & $6 \cdot 8$ & 0.7 & & $0.003 \ddagger$ \\
\hline \multicolumn{7}{|l|}{$C(\mathrm{~F})$} \\
\hline Baseline & 765 & 215 & 768 & 255 & 0.740 & $0.051 \dagger$ \\
\hline 6 months & 714 & 148 & 696 & 134 & 0.733 & $0.051 \ddagger$ \\
\hline \multicolumn{7}{|l|}{$R(\Omega)$} \\
\hline Baseline & 543 & 94 & 566 & 75 & 0.146 & $0.14 \dagger$ \\
\hline 6 months & 533 & 77 & 548 & 74 & 0.416 & $0.14 \ddagger$ \\
\hline \multicolumn{7}{|l|}{$X(\Omega)$} \\
\hline Baseline & $69 \cdot 1$ & $17 \cdot 0$ & $78 \cdot 8$ & $31 \cdot 3$ & 0.073 & $0.002 \dagger$ \\
\hline 6 months & $62 \cdot 4$ & 9.6 & $65 \cdot 2$ & $10 \cdot 4$ & 0.179 & $0.002 \ddagger$ \\
\hline \multicolumn{7}{|l|}{$\mathrm{BCM}(\mathrm{kg})$} \\
\hline Baseline & 23.4 & 5.7 & $22 \cdot 9$ & $5 \cdot 2$ & 0.577 & $0.523 \dagger$ \\
\hline 6 months & 23.0 & 5.5 & 21.5 & 3.9 & 0.299 & $0.523 \ddagger$ \\
\hline \multicolumn{7}{|l|}{ ECM (kg) } \\
\hline Baseline & 24.5 & $4 \cdot 6$ & $22 \cdot 7$ & $5 \cdot 7$ & 0.057 & $0.23 \dagger$ \\
\hline 6 months & 24.9 & 4.8 & $24 \cdot 0$ & $4 \cdot 3$ & 0.601 & $0.23 \ddagger$ \\
\hline \multicolumn{7}{|l|}{ LM (kg) } \\
\hline Baseline & 47.9 & 9.5 & $45 \cdot 6$ & 8.2 & 0.150 & $0.669 \dagger$ \\
\hline 6 months & 48.0 & 8.9 & $45 \cdot 5$ & 8.0 & 0.324 & $0.669 \ddagger$ \\
\hline \multicolumn{7}{|l|}{ LM $(\%)$} \\
\hline Baseline & $62 \cdot 9$ & 0.94 & $61 \cdot 2$ & 0.72 & 0.180 & $0.011 \dagger$ \\
\hline 6 months & 64.4 & 1.06 & $62 \cdot 0$ & 1.05 & 0.120 & $0.43 \ddagger$ \\
\hline \multicolumn{7}{|l|}{ FM (kg) } \\
\hline Baseline & $28 \cdot 7$ & $9 \cdot 7$ & $29 \cdot 2$ & $7 \cdot 6$ & 0.790 & $0.001 \dagger$ \\
\hline 6 months & $27 \cdot 7$ & $9 \cdot 8$ & 28.4 & $9 \cdot 6$ & 0.955 & $0.001 \ddagger$ \\
\hline \multicolumn{7}{|l|}{ FM (\%) } \\
\hline Baseline & $37 \cdot 1$ & 0.9 & 38.8 & 0.7 & 0.170 & $0.002 \dagger$ \\
\hline 6 months & $36 \cdot 3$ & 0.9 & $37 \cdot 7$ & 1.0 & 0.300 & $0.23 \ddagger$ \\
\hline ECM/BCM & & & & & & \\
\hline Baseline & 1.1 & 0.2 & 1.0 & 0.3 & 0.230 & $0.003 \dagger$ \\
\hline 6 months & $1 \cdot 1$ & 0.1 & $1 \cdot 1$ & $0 \cdot 1$ & 0.456 & $0.003 \ddagger$ \\
\hline BMR (kcal)§ & & & & & & \\
\hline Baseline & 1495 & 295 & 1421 & 256 & 0.150 & $0.812 \dagger$ \\
\hline 6 months & 1487 & 286 & 1421 & 249 & 0.445 & $0.812 \ddagger$ \\
\hline ICW (litres) & & & & & & \\
\hline Baseline & 19.4 & 4.9 & $18 \cdot 6$ & 4.2 & 0.480 & $0.031 \dagger$ \\
\hline 6 months & $18 \cdot 6$ & $4 \cdot 1$ & $17 \cdot 6$ & $3 \cdot 2$ & 0.548 & $0.031 \ddagger$ \\
\hline ECW (litres) & & & & & & \\
\hline Baseline & $15 \cdot 8$ & $3 \cdot 1$ & $14 \cdot 6$ & $4 \cdot 1$ & 0.098 & $0.068 \dagger$ \\
\hline 6 months & $16 \cdot 3$ & $2 \cdot 8$ & $15 \cdot 8$ & $2 \cdot 9$ & 0.642 & $0.068 \ddagger$ \\
\hline TBW (litres) & & & & & & \\
\hline Baseline & $35 \cdot 2$ & $6 \cdot 9$ & $33 \cdot 3$ & $5 \cdot 6$ & 0.111 & $0.539 \dagger$ \\
\hline 6 months & $35 \cdot 5$ & $9 \cdot 1$ & $33 \cdot 4$ & 5.5 & 0.335 & $0.539 \ddagger$ \\
\hline TBW/LM & & & & & & \\
\hline Baseline & 73.4 & 1.9 & $73 \cdot 3$ & $1 \cdot 7$ & 0.152 & $0.868 \dagger$ \\
\hline 6 months & 73.4 & 1.6 & 73.5 & 1.9 & 0.855 & $0.868 \ddagger$ \\
\hline TBW/total we & & & & & & \\
\hline Baseline & $46 \cdot 1$ & $5 \cdot 2$ & 44.8 & 3.6 & 0.147 & $0.042 \dagger$ \\
\hline 6 months & 73.4 & 1.6 & 45.5 & $5 \cdot 0$ & 0.314 & $0.042 \ddagger$ \\
\hline
\end{tabular}

$\alpha$, Phase angle; $C$, body capacitance; $R$, resistance $\mathrm{R} ; X$, reactance; $\mathrm{BCM}$, body cell mass; $\mathrm{ECM}$, extracellular mass; $\mathrm{LM}$, lean mass; $\mathrm{FM}$, fat mass; ICW, intracellular water; ECW, extracellular water; TBW, total body water.

${ }^{*}$ Mean values were compared between groups using the Student's $t$ test; within group, comparisons were made using the paired $t$ test.

† Comparisons between baseline and 6-month periods after intervention in G1.

‡ Comparisons between baseline and 6-month periods in $\mathrm{G} 2$.

$\S$ To convert energy in kcal to kJ, multiply by $4 \cdot 184$. 
In enzyme kinetic studies, consumption of retrograded starch depleted total digestible starch and slowed down the rate of intestinal digestion through direct inhibition of $\alpha$-amylase, with important implications for the prevention and management of type 2 diabetes and $\mathrm{CVD}^{(31)}$.

In elderly fragile patients with type 2 diabetes, who used an enteral diabetes-specific formula containing RS IV for 6 weeks, a reduction in the dietary glycaemic response has been proposed as a way to explain the response to the risk of diabetes complications $^{(32)}$. HbA1c, E-selectin and monocyte chemo attractant protein-1 were significantly decreased, tending to decrease the soluble vascular cell adhesion molecule and plasminogen activator inhibitor-1.

In women with pre-diabetes, RS II significantly decreased HbA1c, TNF- $\alpha$ and TAG and increased HDL-cholesterol when compared with placebo, suggesting that RS II is effective as an adjunct therapy in diabetes ${ }^{(33)}$. In addition, RS II may improve glycaemic status, endotoxemia and oxidative stress markers in patients with type 2 diabetes ${ }^{(34)}$.

The mean decrease in HbA1c in our results was $0.3 \%$, similar to the decrease reported in other studies ${ }^{(32,33)}$. In our study, these effects were observed without any change in the anti-diabetic medication. In addition, this is the longest clinical trial evaluating the effects of RS in patients with pre-diabetes and diabetes. Recently, the results of a randomised clinical trial evaluating the 12-week effect of RS in subjects with pre-diabetes were published ${ }^{(35)}$. Compared with controls, RS II did not significantly improve the glycaemic level and other CVD risk factors in prediabetes. These authors showed a reduction $(0 \cdot 1 \pm 0 \cdot 2 \%)$ in HbA1c, with no effect on insulin secretion, insulin sensitivity and the area under the glucose or insulin curves compared with the baseline. The ectopic fat, energy expenditure and other cardiovascular risk factors were unaffected. In our randomised trial, the sample population was larger, and the duration of treatment was longer than in previous studies, and both glucose metabolism and body composition were improved. Our study tested RS from banana biomass in humans.

The effects of acute ingestion of native banana starch on the glycaemic response were assessed by continuous glucose monitoring of obese and lean subjects. The native banana starch reduced the 48-h glycaemia in lean and obese groups separately as well as in a combined group as compared with digestible maize starch. The native banana starch also reduced the postprandial glucose and insulin responses after a meal tolerance test ${ }^{(36)}$

A simple method for preparation of modified starches from banana (Musa $\mathrm{AAB}$ ) and their biological activities were tested in diabetic rats ${ }^{(37)}$. The modified starches exhibited beneficial effects in diabetic rats fed a high-fat diet. The RS III was effective in regulating serum glucose and lipid profile and suppressing the oxidative stress

Prevention of diabetes complications is an important application of RS. The potential implications of dietary RS for glucose homeostasis and kidney health have been assessed in obesityassociated diabetes, examining the mechanisms underlying the protective effect of RS.

Replacing simple carbohydrates by RS could be an effective dietary strategy to prevent hyperglycaemia secondary complications $^{(38)}$.
Our study is in line with the beneficial effects of RS reported in both animal and human studies. Short-term clinical trials provide evidence that different sources of RS can improve glucose metabolism and anthropometric parameters and delay diabetes onset and complications. In view of our results and considering the long duration of our study and its large sample size as compared with previous studies, RS from green banana biomass seems an attractive and inexpensive option for subjects with pre-diabetes or diabetes.

\section{Study limitations and potential bias}

Both diet interventions were not only effective but closely monitored and may have reduced the impact of the active treatment.

In conclusion, these results are promising and encourage the use of new bioactive starches with potential clinical applications to improve glucose metabolism and body composition in subjects with pre-diabetes and diabetes.

\section{Acknowledgements}

E. S. C. participated in the study design, performed data collection, participated in data analyses and interpretation and drafted and approved the final version of the manuscript.

J. T. K., H. T. B. and T. T. F. performed data collection, participated in data analyses and interpretation and revised and approved the final version of the manuscript.

H. A. F. and A. M. F. N. participated in data interpretation and revised and approved the final version of the manuscript.

C. N. F., F. A. F. and M. C. I. participated in the study conception and design, participated in data analysis and interpretation, and drafted, revised and approved the final version of the manuscript.

This study was funded by the National Institute of Science and Technology of Complex Fluids (INCT-FCx) and the Sao Paulo Research Foundation (FAPESP), research grant no. 2008/57685-7. E. S. C. received a research grant from the Coordination for the Improvement of Higher Education Personnel (CAPES). The green banana biomass was a gift from Essência do Vale Alimentos (Cruzeiro, SP, Brazil), which did not influence our results.

There were no conflicts of interest.

\section{Supplementary material}

For supplementary material/s referred to in this article, please visit https://doi.org/10.1017/S0007114519000576

\section{References}

1. American Diabetes Association (2017) Standards of medical care in diabetes - 2017. Diabetes Care 40, Suppl. 1, S33-S43.

2. Garber AJ, Abrahamson MJ, Barzilay JI, et al. (2017) Consensus Statement by the American Association of Clinical Endocrinologists and American College of Endocrinology on the comprehensive type 2 diabetes management algorithm 2017 Executive Summary. Endocr Pract 23, 207-238.

3. Ogurtsova K, da Rocha Fernandes JD, Huang Y, et al. (2017) IDF Diabetes Atlas: global estimates for the prevalence of 
diabetes for 2015 and 2040. Diabetes Res Clin Pract 128, $40-50$.

4. Kaczmarczyk MM, Miller MJ \& Freund GG (2012) The health benefits of dietary fiber: beyond the usual suspects of type 2 diabetes mellitus, cardiovascular disease and colon cancer. Metabolism 61, 1058-1066.

5. Jakobsdottir G, Nyman M \& Fak F (2014) Designing future prebiotic fiber to target metabolic syndrome. Nutrition $\mathbf{3 0}$, 497-502.

6. Slavin J (2013) Fiber and prebiotics: mechanisms and health benefits. Nutrients 5, 1417-1435.

7. Guo Z, Jia X, Zhao B, et al. (2017) C-type starches and their derivatives: structure and function. Ann N Y Acad Sci $\mathbf{1 3 9 8}$, 47-61.

8. Robertson MD, Bickerton AS, Dennis AL, et al. (2005) Insulinsensitizing effects of dietary resistant starch and effects on skeletal muscle and adipose tissue metabolism. Am J Clin Nutr $\mathbf{8 2}$, 559-567.

9. Robertson MD, Wright JW, Loizon E, et al. (2012) Insulinsensitizing effects on muscle and adipose tissue after dietary fiber intake in men and women with metabolic syndrome. J Clin Endocrinol Metab 97, 3326-3332.

10. Johnston KL, Thomas EL, Bell JD, et al. (2010) Resistant starch improves insulin sensitivity in metabolic syndrome. Diabet Med 27, 391-397.

11. Maki KC, Pelkman CL, Finocchiaro ET, et al. (2012) Resistant starch from high-amylose maize increases insulin sensitivity in overweight and obese men. J Nutr 142, 717-723.

12. Birt DF, Boylston T, Hendrich S, et al. (2013) Resistant starch: promise for improving human health. American Society for Nutrition. Adv Nutr 4, 587-601.

13. Evert AB, Boucher JL, Cypress M, et al. (2014) Nutrition therapy recommendations for the management of adults with DM. Diabetes Care 37, Suppl. 1, 120-143.

14. Wheeler ML, Dunbar SA, Jaacks LM, et al. (2012) Macronutrients, food groups, and eating patterns in the management of diabetes: a systematic review of the literature, 2010. Diabetes Care 35, 434-445.

15. American Diabetes Association (2014) Position Statement. Nutrition therapy recommendations for the management of adults with diabetes. Diabetes Care 37, Suppl. 1, S120-S143.

16. Sociedade Brasileira de Diabetes (2016) Diretrizes da Sociedade Brasileira de Diabetes: 2015-2016. São Paulo: AC Farmaceutica.

17. Martins CE \& Cardoso SP (2000) Terapia Nutricional Enteral e Parenteral. Manual de Rotina Técnica. Curitiba: Nutroclínica.

18. Institute of Medicine (IOM) (2005) Dietary references intakes for energy, carbohydrate, fiber, fat, fatty acids, cholesterol, protein and amino acids (macronutrients). https://www.nap.edu/ $\mathrm{read} / 10490 /$ chapter/1 (accessed November 2017)

19. United States Department of Agriculture: Center for Nutrition Policy and Promotion (2017) MyPlate background. http:// www.cnpp.usda.gov/Publications/MyPlate/Backgrounder.pdf (accessed November 2017)

20. Goñi I, García-Díaz L, Mañas E, et al. (1996) Analysis of resistant starch: a method for foods and food products. Food Chem $\mathbf{5 6}$, 445-449.

21. UNICAMP (2011) Tabela Brasileira de composição de alimentos / NEPA-UNICAMP.- 4. ed. rev. e ampl.- Campinas: NEPAUNICAMP (2011) 161 p. http://www.unicamp.br/nepa/taco/ tabela.php?ativo=tabela (accessed October 2012).

22. Philippi ST (2002) Tabela de Composição de Alimentos: Suporte Para Decisão Nutricional. São Paulo: Coronário.

23. Instituto Brasileiro de Geografia e Estatística (IBGE) (2011) Rio de Janeiro: Tabela de composição nutricional dos alimentos consumidos no Brasil: Pesquisa de orçamentos familiares 20082009 (update 2011; cited 1 July 2017). http://biblioteca.ibge .gov.br/visualizacao/livros/liv50002.pdf (accessed November 2017).

24. Slater B, Philippi ST, Marchioni DML, et al. (2003) Validação de Questionários de Frequência Alimentar - QFA: considerações metodológicas. Rev Bras Epidemiol 6, 200-208.

25. Martins CM, Fonseca FA, Ballus CA, et al. (2013) Common sources and composition of phytosterols and their estimated intake by the population in the city of São Paulo, Brazil. Nutrition 29, 865-871.

26. Friedewald WT, Levy RI \& Fredrickson DS (1972) Estimation of the concentration of low-density lipoprotein cholesterol in plasma, without use of the preparative ultracentrifuge. Clin Chem 18, 499-502.

27. Matthews D, Hosker JP, Rudenski AS, et al. (1985) Homeostasis model assessment: insulin resistance and $\beta$-cell function fasting plasma glucose and insulin concentration in man. Diabetologia 28, 412-419.

28. Sun H, Ma X, Zhang S, et al. (2018) Resistant starch produces antidiabetic effects by enhancing glucose metabolism and ameliorating pancreatic dysfunction in type 2 diabetic rats. Int J Biol Macromol 110, 276-284.

29. Hedemann MS, Hermansen K, Pedersen S, et al. (2017) Resistant starch but not enzymatically modified waxy maize delays development of diabetes in Zucker diabetic fatty rats. J Nutr 147, 825-834.

30. Bindels LB, Segura Munoz RR, Gomes-Neto JC, et al. (2017) Resistant starch can improve insulin sensitivity independently of the gut microbiota. Microbiome 5, 12.

31. Patel H, Royall PG, Gaisford S, et al. (2017) Structural and enzyme kinetic studies of retrograded starch: inhibition of $\alpha$-amylase and consequences for intestinal digestion of starch. Carbohydr Polym 164, 154-161.

32. Mesa García MD, García-Rodríguez CE, Rico MC, et al. (2017) A new fructose-free, resistant-starch type IV-enriched enteral formula improves glycaemic control and cardiovascular risk biomarkers when administered for six weeks to elderly diabetic patients. Nutr Hosp 34, 73-80.

33. Gargari BP, Namazi N, Khalili M, et al. (2015) Is there any place for resistant starch, as alimentary prebiotic, for patients with type 2 diabetes? Complement Ther Med 23, 810-815.

34. Karimi P, Farhangi MA, Sarmadi B, et al. (2016) The therapeutic potential of resistant starch in modulation of insulin resistance, endotoxemia, oxidative stress and antioxidant biomarkers in women with type 2 diabetes: a randomized controlled clinical trial. Ann Nutr Metab 68, 85-93.

35. Peterson CM, Beyl RA, Marlatt KL, et al. (2018) Effect of $12 \mathrm{wk}$ of resistant starch supplementation on cardiometabolic risk factors in adults with prediabetes: a randomized controlled trial. Am J Clin Nutr 108, 492-501.

36. Jiménez-Domínguez G, Ble-Castillo JL, Aparicio-Trápala MA, et al. (2015) Effects of acute ingestion of native banana starch on glycemic response evaluated by continuous glucose monitoring in obese and lean subjects. Int J Environ Res Publ Health 12, 7491-7505.

37. Reddy CK, Suriya M, Vidya PV, et al. (2017) Synthesis and physico-chemical characterization of modified starches from banana (Musa AAB) and its biological activities in diabetic rats. Int J Biol Macromol 94, 500-507.

38. Koh GY \& Rowling MJ (2017) Resistant starch as a novel dietary strategy to maintain kidney health in diabetes mellitus. Nutr Rev 75, 350-360. 